\title{
Formula Optimization of Antimicrobial Hand Sanitizer With Lemongrass Essential Oil
}

\author{
Dyani Primasari Sukamdi ${ }^{1, *}$ Muhammad Fariez Kurniawan ${ }^{2}$ Vella Lailli Damarwati ${ }^{3}$ \\ 1, 2, 3 Universitas Muhammadiyah Yogyakarta \\ *Email: dyani.primasaris@umy.ac.id
}

\begin{abstract}
During the covid-19 pandemics, the government required people to comply with health protocols. Some health protocol demands are such as using masks and maintaining personal sanitation independently. The application of sanitation and hygiene aims to protect the public from the covid-19 virus. Independently, people are encouraged to wash their hands well before and after doing all kinds of activities. In terms of sanitation needs, hand sanitizer is considered to play an essential role because of its practicality to be carried everywhere. However, with so many people trying to make hand sanitizers, making hand sanitizers quality cannot be assured. Therefore, this study aims to create an optimal hand sanitizer formula. The study was conducted by comparing three basic liquid hand sanitizer formulas. The basic formula consists of alcohol $73 \%$, aquadest $19.57 \%$, and glycerine $0.83 \%$. Differences between the three formulas are in the essential's oils 6.6\% (Formula 1: Citronella, Formula 2: Lemongrass, Formula 3: Citrus). The formula was then tested physically and organoleptically to identify the quality of the hand sanitizer produced. Test results were compared to each other to obtain the most optimal formula. The result of organoleptic, $\mathrm{PH}$ test, homogeneity test and the favourite test showed that the best formula was formula number 3. Formula number 3 showed good clarity, fresh and had distinctiveness essential oils aroma on hand. Based on these results, formula 3 was continued with microbiology testing. The microbiological test was carried out with inhibition zone observation: well inhibition methods and bacteria-killing power. Microbiological tests showed the similarity of average inhibition zones $(0.3039 \mathrm{~mm})$ with the market product $(0.3178 \mathrm{~mm})$ and average bacteria-killing power of product (77.6\%) higher than market product (67.1\%). This result showed that there was Hand sanitizer with lemongrass oil had similar effectivity to killing bacteria.
\end{abstract}

\section{Keywords: Covid-19, Essential Oil, Hand sanitizer, Formulation, Lemongrass}

\section{INTRODUCTION}

During the Covid-19 pandemic, humans are obliged to carry out self-sanitation as well as possible. Sanitation can be carried out by washing hands properly and using a hand sanitizer. Self-sanitation aims to protect ourselves from being exposed to bacteria. Hand sanitizers are carried out due to the need for rapid and effective self-sanitation [1]. It encourages ordinary people to produce hand sanitizers of poor quality.

Hand sanitizer products can be found in various forms, including liquid and gel forms. Its primary function is to maintain practical hand hygiene, to reduce exposure to disease-causing microorganisms. Hand sanitizer bases can be alcoholic and non-alcoholic. The hand sanitizer recommended by the World Health Organization is alcoholbased [1]. The main ingredients in alcohol-based hand sanitizers can be ethanol, isopropyl alcohol, hydrogen peroxide, aquadest, glycerin, and other additives.

Hand sanitizers can be added with additional substances as antiseptic and antibacterial. Examples of additives that can be used as antiseptics and antibacterial can come from plants essentials oils; such as lemongrass, citronella, and lime
[2][3][5]. Antiseptic and antibacterial are compounds used to kill or inhibit the growth of bacterial microorganisms in living tissue. Based on that data, this study on the hand sanitizer formulation aims to obtain an alternative formula for the layman that can be used as an antiseptic and antibacterial. 


\section{MATERIALS AND METHODS}

\subsection{Materials}

The materials used for the hand sanitizer formula were alcohol 96\%, Aquadest, Glycerin, Citronella essential oil, Lemongrass essential oil, and Citrus essential oil. products. The test was carried out by looking at the presence or absence of black and white background.

\subsubsection{Microbiological Test}

Microbiological tests were carried out on 1 formula chosen by the respondent. The test was carried out at the Agrobiotechnology Laboratory, Faculty of Agriculture,

Table 1. Ingredients of Hand Sanitizer Formula (per $100 \mathrm{~mL}$ )

\begin{tabular}{|c|c|c|c|}
\hline Ingredients & Formula $1(\mathrm{~mL})$ & Formula $2(\mathrm{~mL})$ & Formula $3(\mathrm{~mL})$ \\
\hline Alcohol 96\% & 73 & 73 & 73 \\
\hline Aquadest & 27 & 27 & 27 \\
\hline Glycerin & 0.83 & 0.83 & 0.83 \\
\hline Essentials oil & Citronella: 6.6 & heitrest: Eornducte & edsenongrassingit \\
\hline
\end{tabular}

\subsection{Methods}

In the first step we produce hand sanitizer formulas with three types of essential oils. The three hand sanitizer formulas were tested for some of their physical properties, namely the $\mathrm{pH}$ test, organoleptic test, and particle test. Based on the data results three test, the selected formula was continued to the respondent's preference test. The formula results were most likely to be preferred by respondents and were tested in microbiology as the final result of hand sanitizer.

\subsubsection{Formulating Hand Sanitizers}

Equipment was sterilized before used to kill microbes. Making the hands sanitizer began by measuring the volume of all the ingredients needed (Table 1). First, alcohol $96 \%$ was put in a container, then added aquadest, glycerin, and essential oils. Whole materials were stirred until they were mixed.

\subsubsection{Evaluation of Hand Sanitizers}

\subsubsection{PH Test}

0.5 milliliters of formula were put and $\mathrm{PH}$ was measured using a PH-meter, and the results were recorded. This test aimed to determine whether the preparation could be used at the PH of human skin $(4,5-7,0)$ [5], as it was used on hands later.

\subsubsection{Organoleptic Test}

Organoleptic tests were carried out by looking at the shape, color, and smell of the preparations. Liquid hand sanitizers should be clear, non-lumpy, easy to pour and have a distinctive smell of each essential oil.

\subsubsection{Particle Visibility Test}

Particle tests were carried out by observing the liquid hand sanitizers whether there were deposits or particles in the
Escherichia coli with the well diffusion method and the calculation of the Escherichia coli population with each replication 3 times and compared to the market product.

\section{RESULTS AND DISCUSSION}

WHO published a guide to local production: WHOrecommended Handrub Formulations [6] which contained guidelines for the community to make their hand sanitizers with materials easily available in general and for use. This recommended hand sanitizer formula was liquid forms. A good hand sanitizer recommended by WHO [1], for $1000 \mathrm{~mL}$, contained: alcohol $96 \% \mathrm{v} / \mathrm{v}, 833.3 \mathrm{~mL}$; hydrogen peroxide $3 \% \mathrm{v} / \mathrm{v}, 41.7 \mathrm{~mL}$; glycerol $98 \% \mathrm{v} / \mathrm{v}, 14.5 \mathrm{~mL}$ and sterile distilled or boiled water; or isopropyl alcohol $99.8 \% \mathrm{v} / \mathrm{v}$, $751.5 \mathrm{~mL}$; hydrogen peroxide 3\% v/v, $41.7 \mathrm{~mL}$; glycerol $98 \%$ $\mathrm{v} / \mathrm{v}, 14.5 \mathrm{~mL}$ and sterile distilled or boiled water.

The formula used in this study consisted of the following ingredients: 96\% alcohol, 98\% glycerin, essential oils, and aquadest. There were various formulas in the essential oil used. The aroma variants of essential oils in this study were: Citronella (Cymbopogon nardus) (formula 1), Lime (Citrus aurantifolia s.) (formula 2) and Lemongrass (Cymbopogon citratus) (formula 3). The first step was to mix all the ingredients according to their volume.

After all the ingredients were mixed, the ingredients were evaluated. Results of hand sanitizer evaluation were as follows:

\subsection{PH-Test}

The first evaluation was the $\mathrm{PH}$ test using a PH-meter. The results obtained were the formula had a $\mathrm{PH}$ of 6.0 ; indicating it was in accordance with the skin's $\mathrm{PH}$ range. If the preparation's $\mathrm{pH}$ was in accordance with the skin's $\mathrm{pH}$ range, the risk of skin irritation could be minimized [5]. 
Table 3. Result of Microbiological Test: Inhibition of Escherichia coli Well Diffusion Method

\begin{tabular}{|l|l|r|}
\hline Sample & Repetition & Well Diffusion Methods (mm) \\
\hline Market Product & 1 & $0.187 \pm 0.22$ \\
\cline { 2 - 3 } & 2 & $0.200 \pm 0.19$ \\
\cline { 2 - 3 } & 3 & $0.567 \pm 0.22$ \\
\cline { 2 - 3 } & Means & 0.3178 \\
\hline Hand sanitizer with Lemongrass & 1 & $0.130 \pm 0.16$ \\
\cline { 2 - 3 } & 2 & $0.335 \pm 0.08$ \\
\cline { 2 - 3 } & 3 & $0.447 \pm 0.10$ \\
\cline { 2 - 3 } & Means & 0.3039 \\
\hline
\end{tabular}

\subsection{Organoleptic Test}

Furthermore, the organoleptic test was carried out. The results of the organoleptic test were precise preparations, no lumps, easy to pour, and the aroma showed the distinctiveness of Citronella (Cymbopogon nardus) (formula 1), Lime (Citrus aurantifolia s.) (formula 2) and Lemongrass (Cymbopogon citratus) (formula 3) essential oils. The results of the aroma test were strengthened by the preference test on 21 respondents, which stated the following results (Table 2):

Based on the results (Table 2) of the organoleptic test, formula 3 was the most accepted formula by 9 respondents.

Table 2. Results of the Aroma of Hand Sanitizers Preferred Test

\begin{tabular}{|l|c|}
\hline \multicolumn{1}{|c|}{ Essential Oils Aroma } & $\begin{array}{l}\text { The number of } \\
\text { respondents who voted }\end{array}$ \\
\hline $\begin{array}{l}\text { Citronella (Cymbopogon } \\
\text { nardus) }\end{array}$ & 5 \\
\hline Lime (Citrus aurantifolia s.) & 6 \\
\hline $\begin{array}{l}\text { Lemongrass (Cymbopogon } \\
\text { 3. Particle Visibility Test } \\
\text { citratus) }\end{array}$ & 9 \\
\hline
\end{tabular}

Particle test were carried out by observing the liquid hand sanitizers whether deposits or particles in the products. The test was carried out by looking at the presence or absence of black and white background. The results of the particle test showed that there were no black and white particles in the three-hand sanitizer preparations. The three test results can be concluded that Formula 3 is the formula most accepted by respondents.

\subsection{Microbiological Test}

Microbiological tests were carried out on 1 formula chosen by the respondent. The test was carried out at the Agrobiotechnology Laboratory, Faculty of Agriculture, UMY. The test conducted was the test for the inhibition of Escherichia coli with the well diffusion method and the calculation of the Escherichia coli population with each replication 3 times and compared to the market product. The
列 Lemongrass essential oil had almost the same inhibition power as the market product used as a comparison.

Hand sanitizer with alcohol has been shown to kill grampositive and negative bacteria [7]. WHO [1] agreed with this opinion as it was included in one of the recommendations for using alcohol-based hand sanitizers: evidence-based, intrinsic advantages of fast-acting and broad-spectrum microbicidal activity with minimal risk of generating resistance to antimicrobial agents. The essential oils used in hand sanitizer formulas were essential oils that had an antibacterial effect. Citronella (Cymbopogon Nardus) contained citronellal, geraniol, and citronellol which had antibacterial effects [8]. Lime plants (Citrus aurantifolia s.) Also contain flavonoid glycosides, namely eriocitrin, hesperidin and neoponcirin which had pharmacological activity as antibacterial [4]. Lemongrass (Cymbopogon Citratus) contained $\alpha$-citral (geranial) and $\beta$-citral (neral), whose characteristics had antibacterial effects with predominant activities against grampositive and negative bacterial isolates.

It further strengthened the potential of natural ingredients as antibacterial agents. For example, the three essential oils used contained many compounds that had antibacterial pharmacological effects. The content of these compounds could support alcohol activity as antiseptic agents. Alcohol, used as one of the ingredients in hand sanitizers, was considered as effective as hand soap. Comparison of hand sanitizers with antiseptic products on the market was carried out in this study. Based on the results similar to the product market antiseptic, it can be said that hand sanitizer with Lemongrass (Cymbopogon citratus) had the same activity as the product market.

Table 4. Result of Microbiological Test Inhibition of Escherichia coli with The Calculation of Bacterial Population

\begin{tabular}{|l|c|c|}
\hline \multirow{2}{*}{ Sample } & \multicolumn{2}{|c|}{ Repetition } \\
\cline { 2 - 3 } & CFU/mL & $\%$ \\
\hline Market Product & $144 \times 10^{7}$ & 67.1 \\
\hline $\begin{array}{l}\text { Hand sanitizer with } \\
\text { Lemongrass }\end{array}$ & $167 \times 10^{7}$ & 77.6 \\
\hline
\end{tabular}




\section{CONCLUSION}

- Lemongrass contained compounds that had pharmacological activity as antibacterial.

- Hand sanitizer with lemongrass was the most common vote from respondents.

- Hand sanitizer with lemongrass essential oil had the same bacterial inhibitory effect as the market product.

\section{REFERENCES}

[1] World Health Organization, "WHO Guidelines on Hand Hygiene in Health Care, First Global Patient Safety Challenge Clean Care is Safer Care" WHO Press, 2009, pp 49.

[2] O.S. Oladeji, F.E. Adelowo, D.T. Ayodele, and K.A. Odelade, "Phytochemistry and Pharmacological activities of Cybopogon citratus: A Review", Scientific African 6 e00137, 2019.

[3] B. G. Cunha, C. Duque, K.S. Caiaffa, L. Massunari, I.A. Catanoze, D.M. D. Santos, S.H.P.D Oliveira, and A.M. Guiotti, "Cytotoxicity and Antimicrobial Effects of Citronella Oils and Commercial Mouthwashes on S. aureus and C. albicans Biofilms in Prosthetic Materials", Archives of Oral Biology 109: 10577, 2020.

[4] S. S. Prastiwi, F. Ferdiansyah, "An Article Review: Ingredients and Pharmacological Activity of Lime (Citrus aurantifolia s.)", Farmaka, vol. 15 no 2, 2017.

[5] A.K. Zulkarnain, N. Ernawati, and N.I. Sukardani, "Activities of Yam Starch (Pachyrrizus Erosus (L.) Urban) as Sunscreen in Mouse and The Effects of Its Concentration to Viscosity Level", Traditional Medicine Journal, Vol 18(1), 2013.

[6] World Health Organization, "Guide to Local Production: WHO-recommended Handrub Formulations", WHO Press, 2010.

[7] S.E. Czerwinski, J. Cozean, and C. Cozean, "Novel Water-Based Antiseptic Lotion Demonstration Rapid, Broad-Spectrum Kill Compared With Alcohol Antiseptic", Journal of Infection and Public Health, vol 7, 2014, pp 199-204.

[8] W. Bota, M. Martosupono, and F.S. Rondonuwu, "Potential of Citronella Oil Compounds from Cymbopogon nardus L. Plants as Antibacterial Agents", National Conference of Science and Technology Engineering Faculty of Universitas Muhammadiyah Jakarta, 2015. 